\title{
A Novel Dual Ultrawideband CPW-Fed Printed Antenna for Internet of Things (IoT) Applications
}

\author{
Qasim Awais, ${ }^{1}$ Hassan Tariq Chattha $\mathbb{D}^{1},{ }^{2}$ Mohsin Jamil $\mathbb{D}^{\mathrm{D}},{ }^{2,3}$ Yang Jin, \\ Farooq Ahmad Tahir $\left(\mathbb{1},{ }^{3}\right.$ and Masood Ur Rehman $\left(\mathbb{1}^{4}\right.$ \\ ${ }^{1}$ Department of Optoelectronic Engineering, Chongqing University, Chongqing, China \\ ${ }^{2}$ Department of Electrical Engineering, Faculty of Engineering, Islamic University of Madinah, Al-Madinah, Saudi Arabia \\ ${ }^{3}$ National University of Sciences and Technology (NUST), Islamabad, Pakistan \\ ${ }^{4}$ Department of Computer Science and Technology, University of Bedfordshire, Luton, UK
}

Correspondence should be addressed to Hassan Tariq Chattha; chattha43@hotmail.com

Received 30 November 2017; Accepted 12 February 2018; Published 28 March 2018

Academic Editor: Luca Reggiani

Copyright (C) 2018 Qasim Awais et al. This is an open access article distributed under the Creative Commons Attribution License, which permits unrestricted use, distribution, and reproduction in any medium, provided the original work is properly cited.

\begin{abstract}
This paper presents a dual-band coplanar waveguide (CPW) fed printed antenna with rectangular shape design blocks having ultrawideband characteristics, proposed and implemented on an FR4 substrate. The size of the proposed antenna is just $25 \mathrm{~mm} \times$ $35 \mathrm{~mm}$. A novel rounded corners technique is used to enhance not only the impedance bandwidth but also the gain of the antenna. The proposed antenna design covers two ultrawide bands which include $1.1-2.7 \mathrm{GHz}$ and $3.15-3.65 \mathrm{GHz}$, thus covering $2.4 \mathrm{GHz}$ Bluetooth/Wi-Fi band and most of the bands of 3G, 4G, and a future expected 5G band, that is, 3.4-3.6 GHz. Being a very lowprofile antenna makes it very suitable for the future $5 \mathrm{G}$ Internet of Things (IoT) portable applications. A step-by-step design process is carried out to obtain an optimized design for good impedance matching in the two bands. The current densities and the reflection coefficients at different stages of the design process are plotted and discussed to get a good insight into the final proposed antenna design. This antenna exhibits stable radiation patterns on both planes, having low cross polarization and low back lobes with a maximum gain of $8.9 \mathrm{~dB}$. The measurements are found to be in good accordance with the simulated results.
\end{abstract}

\section{Introduction}

Internet of Things (IoT) applications incorporate major advancements of computer networking, microelectronics and modern communication system. This technology enables physical sensing and actuating devices to be controlled remotely over the Internet. To attain reliable communication, these devices are required to be compact, cost-effective, and energy efficient to operate on multibands for LTE, WLAN (IEEE $802.11 \mathrm{a} / \mathrm{b} / \mathrm{g} / \mathrm{n}$ ), WiMAX (IEEE 802.16), ZigBee (IEEE 802.15.4), GSM (800 MHz, $850 \mathrm{MHz}$, and $1900 \mathrm{MHz}$ ), and so on. Scope for Internet of Things (IoT) operating on these bands can be seen as in 2003; the world population was 6.3 billion and connected devices per person were $0.0793 \%$, while with population grown to 7.2 billion in 2015 , revolutionized connected devices per person increased to $3.4 \%$. This trend is expected to grow exponentially so the demand for smaller devices along with the better antenna module will grow as well. Due to miniaturization of embedded systems, multiple modules can be assembled on these small gadgets to improve efficiency, reliability, and robustness for various scenarios of environmental monitoring, smart cities, smart healthcare, smart grid, military/defense, and so on $[1,2]$.

Apart from the many advantages of power options, flexibility, ease of installation, and replacement there are numerous challenges of scalability, fault tolerance, energy harvesting, and security issues which need to be addressed for worldwide acceptability [3]. The antenna system, being the front end of all hand-held communication devices is expected to cover all major frequency bands of IEEE 802.11 (2.4-2.48 GHz) and IEEE 802.15.4 (2.5-2.69 GHz/ 3.4-3.69 GHz/5.25-5.85 GHz) with acceptable gain and radiation pattern for multiple integrated services. Further, it is anticipated that modern antenna design should be flexible 
TABLE 1: Comparison between different existing CPW designs and our proposed work.

\begin{tabular}{|c|c|c|c|c|}
\hline References & Type & Total area $\left(\mathrm{mm}^{2}\right)$ & Bandwidth & Peak gain $(\mathrm{dBi})$ \\
\hline$[12]$ & Dual-band & 1020 & $2.3-2.5$ and $2.9-15.0 \mathrm{GHz}$ & 2.5 \\
\hline [13] & Dual-band & 900 & $1.86-1.97$ and $3.0-12.0 \mathrm{GHz}$ & 3.0 \\
\hline$[14]$ & Dual-band & 1250 & $3.4-3.6$ and $8-15 \mathrm{GHz}$ & -.---- \\
\hline [15] & Tri-band & 1600 & $2.28-2.58,3.38-3.66$, and $5.07-5.86 \mathrm{GHz}$ & 3.3 \\
\hline [16] & Tri-band & 839.5 & $2.33-2.76,3.05-3.88$, and $5.57-5.88 \mathrm{GHz}$ & 2.8 \\
\hline [17] & Dual-band & 2700 & $2.26-2.57$ and $4.81-6.56 \mathrm{GHz}$ & 3.2 \\
\hline [18] & Dual-band & 1500 & $2386-2510$ and $4878-6002 \mathrm{MHz}$ & 2.6 \\
\hline [19] & Tri-band & 896 & $2.3-2.8,3.1-4.0$ and $4.6-5.3 \mathrm{GHz}$ & 3.0 \\
\hline \multirow[t]{2}{*}{ [20] } & Dual-band & 1400 & $2.2-2.55$ and $3.0-5.6 \mathrm{GHz}$ & 2.0 \\
\hline & Proposed work & 875 & $1.1 \mathrm{GHz}-2.7 \mathrm{GHz}$ and $3.15-3.65 \mathrm{GHz}$ & $8.9 \mathrm{~dB}$ \\
\hline
\end{tabular}

enough to regulate impedance bandwidth for various center frequencies independently [4].

Some well-known techniques such as slots in the radiating patch, defected ground structures (DGS), engraving strips on antenna, and the induction of band notched structures in the designs have been adopted to satisfy the abovementioned characteristics $[4,5]$. Apart from these orthodox methods, the use of metamaterials and complementary split ring resonator (CSRR) techniques are employed in literature for getting higher gain in order to reduce cross frequency interference. Ahmed et al. implemented a magneto-electric (ME) dipole antenna that showed wide impedance bandwidth, better gain, and matching radiation patterns on both E-plane and $\mathrm{H}$ plane [6]. But such cross-magneto-electric structures are not suitable for mass production in Internet of Things (IoT) due to the large size and sensitive design parameters. On the other hand, the coplanar waveguide method has advantages such as wide bandwidth, uniplanar design and ease of installation with MMIC, and active components, making it more suitable for targeted IoT applications.

Various CPW-fed antennas have been reported in literature such as multiband [3-8], CPW antennas with added strip for WLAN [9-11], and asymmetric coplanar strip antennas [12-20]. However, majority of these designs have large antenna dimensions and do not cover all the major bands of WLAN/WiMAX/LTE [13-16, 18]. Dual-band antenna in [21] with an average gain of $2.5 \mathrm{~dB}$ having dimensions $25 \mathrm{~mm}$ $\times 25 \mathrm{~mm}$ being compact in size operates only in WLAN band. Further, in some other designs, the antenna gains and reflection coefficient parameters are not impressive compared to the antenna dimensions [15-20, 22-25]. In [26], a CPWfed multiband antenna having dimension $70.4 \mathrm{~mm} \times 45 \mathrm{~mm}$ is implemented having an impedance bandwidth of $127 \mathrm{MHz}$ for WiMAX band only. Similarly, a $70 \mathrm{~mm} \times 70 \mathrm{~mm}$ CPW-fed WLAN antenna implemented in [27] operating at $2.4 \mathrm{GHz}$ with peak gain of $6.5 \mathrm{~dB}$ has a very low impedance bandwidth. The rounded corners concept is found in literature to enhance the overall gain, with stable radiation patterns [22-25]. Moreover, frequency dispersion is reduced and current is uniformly distributed on radiation surface corners using this procedure. Adjustable strips in our design enabled CPW design to improve bandwidth over higher frequency bands

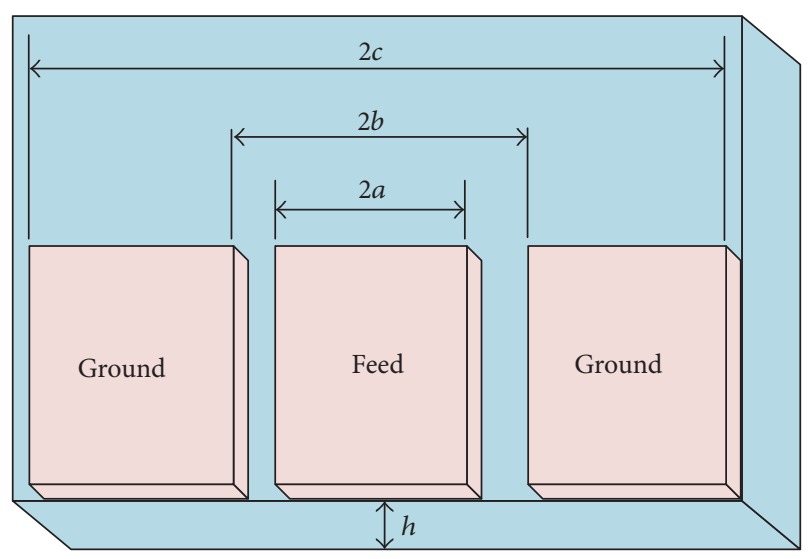

FIGURE 1: Feed line calculation in CPW design.

without compromising the overall size of $875 \mathrm{~mm}^{2}$. In order to reduce size and avoid the complexity, major overlapped slots have been introduced in the proposed antenna design along with two strips above and below the main radiating patch. Compact ground plane length ratio to the overall length of the antenna is optimized to achieve $50 \mathrm{Ohm}$ impedance matching by adjusting the microstrip width and gap between the microstrip and the sides of the ground plane $[6,8,24]$. In Table 1 , a comparison is made between different existing CPW designs found in literature and our proposed work. Design working principle and antenna dimensions are explained in the following sections along with the detailed simulated and experimental results.

\section{Design Specifications}

The feed line calculation in CPW design is depicted in Figure 1, whereas the detailed geometry of the proposed antenna is shown in Figure 2. The antenna is fabricated on an FR4 substrate with relative permittivity of 4.4 having a standard thickness of $1.6 \mathrm{~mm}$. The length, width, and the wavelength of the main rectangular patch is calculated and gradually modified by calculating the resonant frequencies 


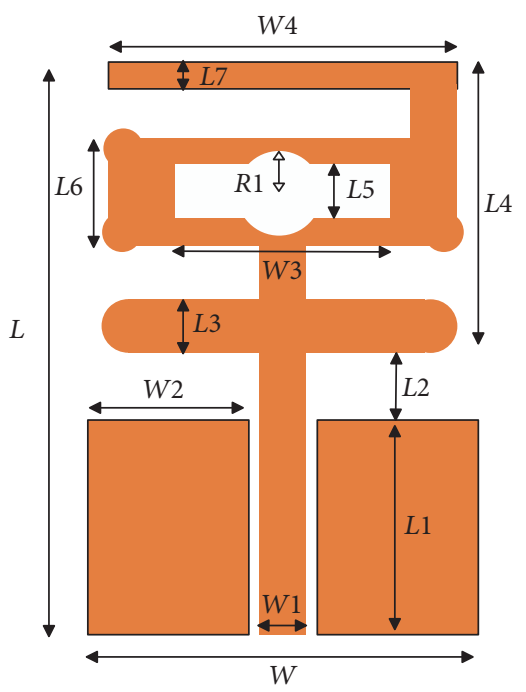

(a)

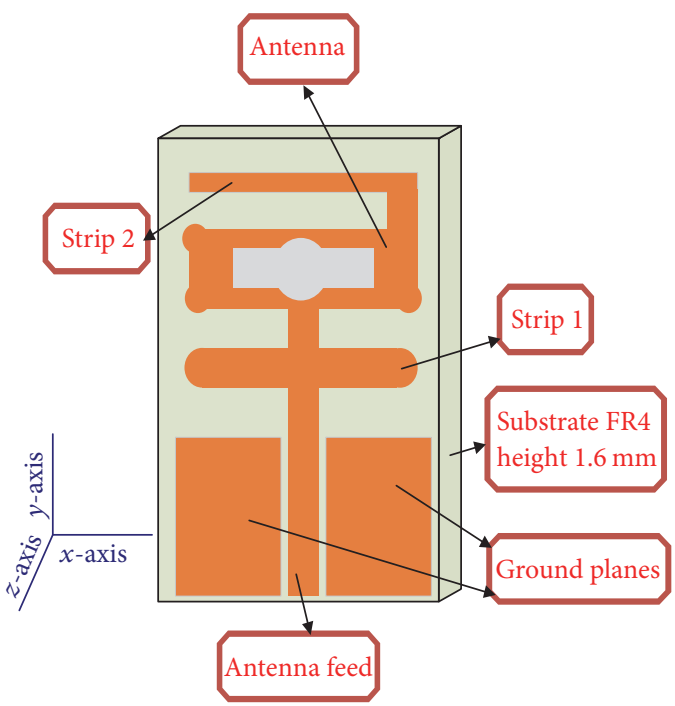

(b)

FIGURE 2: Geometry of the proposed antenna: (a) parametric details and (b) major components of proposed antenna.

TABLE 2: Proposed CPW antenna design parameters values.

\begin{tabular}{lcccccccc}
\hline Parameter & $L$ & $W$ & $L 1$ & $W 1$ & $L 2$ & $W 2$ & L3 \\
\hline Value/mm & 35 & 25 & 14.8 & 2 & 3.7 & 10.5 & 2 & W3 \\
Parameter & $L 4$ & $W 4$ & $L 5$ & $L 6$ & $R 1$ & $L 7$ & $h$ \\
Value/mm & 14.3 & 17 & 3 & 7 & 2.5 & 0.5 & 9 \\
\hline
\end{tabular}

for first and second resonance bands using the following expressions for coplanar waveguide design.

$$
\begin{aligned}
L 4 & =\frac{c}{4 f_{\min } \sqrt{\varepsilon_{r . \mathrm{eff}}}} \\
L 2 & =\frac{c}{4 f_{\max } \sqrt{\varepsilon_{r . \mathrm{eff}}}} \\
f 1 & =\frac{c}{4 Y_{g} \sqrt{\varepsilon_{r . \mathrm{eff}}}} \\
\varepsilon_{r . \mathrm{eff}} & =\frac{\varepsilon_{r}+1}{2},
\end{aligned}
$$

where " $c$ " is the speed of light, $\varepsilon_{r \text {.eff }}$ is the effective relative permittivity of substrate which is equal to 2.7 , and " $Y_{g}$ " is the guided wavelength which depends on the length of upper and lower strips for both bands. Characteristics impedance of the feed line having finite width ground planes on each side of FR4 substrate is given by Van Caekenberghe et al. [28].

$$
Z o=\frac{30 \pi}{2 \sqrt{\varepsilon_{r . \mathrm{eff}}}} \frac{K(k)}{K\left(k^{\prime}\right)} \Omega,
$$

where " $K$ " is complete elliptic integral of first iteration and " $k$ " and " $k$ " are CPW line dependent variables. These two parameters are calculated as follows:

$$
\begin{aligned}
k & =\frac{c}{b} \sqrt{\frac{b^{2}-a^{2}}{c^{2}-a^{2}}} \\
k^{\prime} & =\sqrt{1-k^{2}}=\frac{a}{b} \sqrt{\frac{c^{2}-b^{2}}{c^{2}-a^{2}}} .
\end{aligned}
$$

Center frequencies $f_{1}$ and $f_{2}$ are calculated from (3) and optimized using Ansoft's High Frequency Structure Simulator (HFSS) software package.

The strip lengths $L 4$ and $L 2$ are optimized close to a quarter wavelength of center frequency considering $f_{\min }$ around $2.1 \mathrm{GHz}$ and $f_{\max }$ at $3.6 \mathrm{GHz}$. The gap between the ground and feed elements " $g$ " is $1 \mathrm{~mm}$ and the length of the feed line is $18.7 \mathrm{~mm}$, while the radius of small rounded corners on the main antenna segment is $1.4 \mathrm{~mm}$. The detailed antenna design parameters values are illustrated in Table 2. The gap between the one of the ground planes and feed line is optimized through simulation software to be $1 \mathrm{~mm}$. Band stop function is realized by adding overlapped rectangular and circular slot in the main rectangular radiator. This reduces 


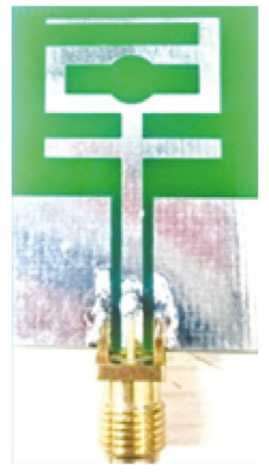

(a)

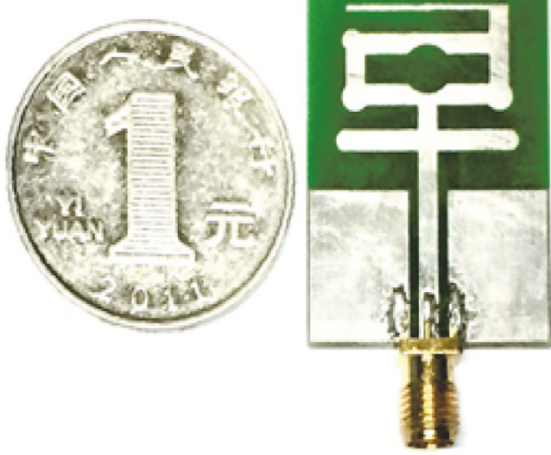

(b)

FIGURE 3: Fabricated antenna prototypes of (a) evolved antenna design and (b) proposed CPW antenna.

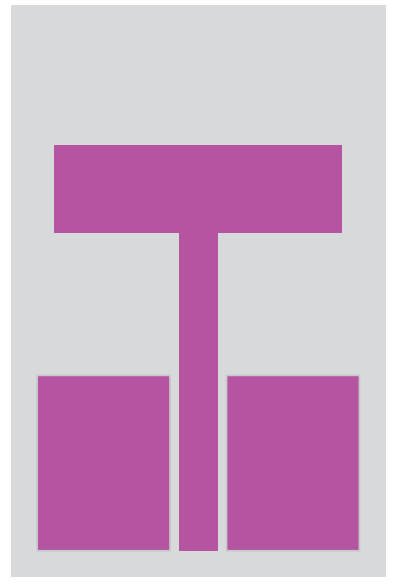

(a)

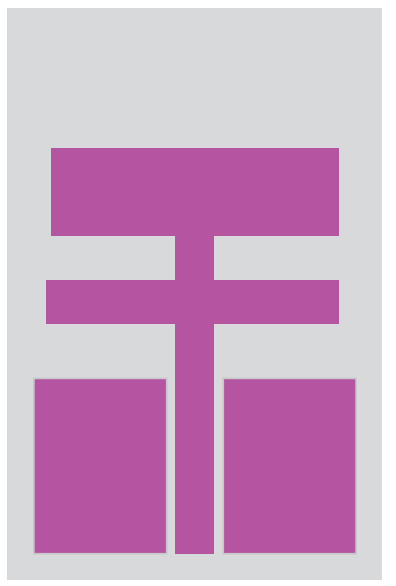

(b)

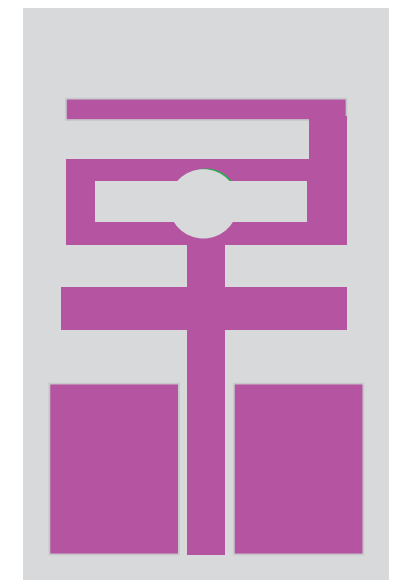

(c)

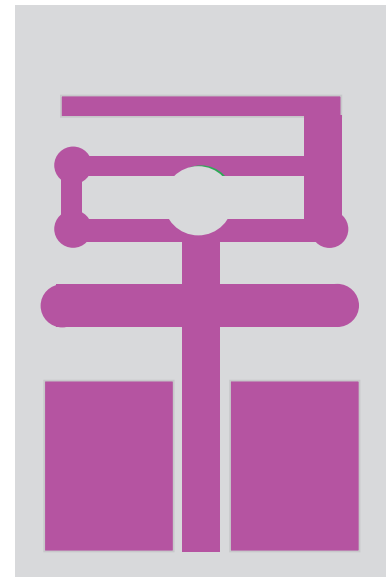

(d)

FIgUre 4: Evolution process of antenna: (a) Antenna 1, (b) Antenna 2, (c) Antenna 3, and (d) final proposed antenna.

the interference and creates notched frequencies between 2.4 GHz and $3.4 \mathrm{GHz}$ bands. Similar kind of reactively loaded CPW antenna in [29] shows promising results with y-shaped and $\mathrm{u}$-shaped slots in rectangular patch. In literature, various shapes of the slots are used to enhance the bandwidth of CPW designs including square wavelength line slot, fractal shaped slots, asymmetrical CPW slots, and circular slots [2527, 29-32]. Square shaped slot implemented in [33] showed ultrawideband bandwidth and reduced overall antenna size effectively.

The method of overlapped symmetrical rectangular and circular slots is embedded in our proposed antenna to reduce interference of adjacent frequency bands to obtain efficient antenna parameters. To determine a good impedance matching, the electrical wavelength of the top and bottom strips is kept close to the quarter wavelength along with wideband microstrip coplanar strip line to couple the electromagnetic energy for better radiation efficiency. Similar kinds of small slit loaded antennas in $[31,32,34]$ use series inductive slits and rectangular and circular shaped slots for impedance bandwidth improvement. Through iterative simulations, it is experienced that wider overlapped circular and rectangular slots are more productive in widening the impedance bandwidth and improving antenna gain.

\section{Antenna Performance}

The fabricated prototypes of the two final designs are shown in Figure 3. The simulations are performed in Ansoft's HFSS and the reflection coefficients of the proposed antenna are measured using a Vector Network Analyzer (E5072A). An SMA connector is carefully coupled with ground and feed structures to obtain measurements.

3.1. Antenna Evolution. The evolution process of final antenna is shown in Figures 4(a)-4(d). Simulated reflection coefficient results for all antenna design steps/types are depicted in Figure 5. The antenna design process is started from a coplanar waveguide fed printed antenna by attaching a rectangular patch with feed line that attains a very broad fractional impedance bandwidth of more than $100 \%$ (1.1 GHz-3.9) $\mathrm{GHz}$ for $S_{11}<-10 \mathrm{~dB}$ threshold without having second resonant band. However, our design goal is to make a dual-band antenna in which each band tuned/modified 


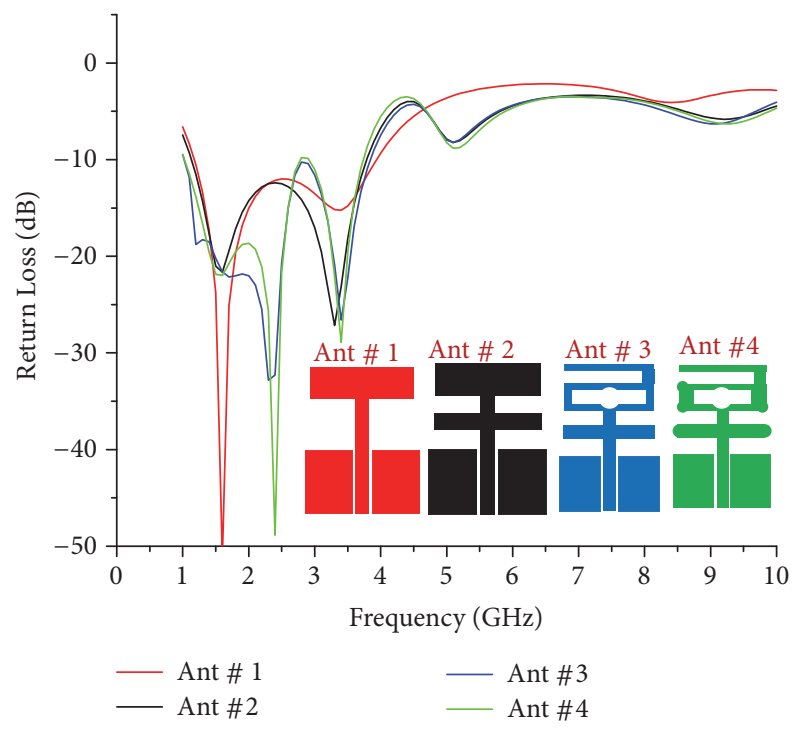

FIGURE 5: Simulated reflection coefficients of the four antennas.

comparatively independently without significantly affecting the other band as per our design needs. The 2 nd design goal is to increase the gain of the antenna as CPW-fed printed antennas are generally omnidirectional antennas. In order to achieve these design goals, Antenna 1 is modified by adding an additional rectangular strip that creates a second resonance around $3.4 \mathrm{GHz}$ as shown in Figure 4(b). Antenna 3 is created by adding another top strip and etching overlapped slots in first rectangular patch that shows first resonance at $2.4 \mathrm{GHz}$ with impedance bandwidth from $1.0 \mathrm{GHz}$ to $2.7 \mathrm{GHz}$ and a second resonance at $3.4 \mathrm{GHz}$ with impedance bandwidth from around $3.1 \mathrm{GHz}$ to $3.7 \mathrm{GHz}$. Finally, Antenna 4 (proposed) is simulated and fabricated with imbedded rounded corners technique for improved performance in terms of reflection coefficient and gain. This design attains dual bands with a simulated result of around $80 \%$ fractional bandwidth $(1.1 \mathrm{GHz}-2.8 \mathrm{GHz})$ in the first band and around $23 \%$ fractional impedance bandwidth $(3.0 \mathrm{GHz}-3.75 \mathrm{GHz})$ in the second resonance band. This is worth mentioning that $S_{11}$ has shown better notched frequency characteristic between the two bands. On the other hand, it is noted that introducing rounded corners has a very low effect on the resonant frequencies, but it has effectively improved the fractional impedance bandwidth and the gain of the final antenna design. Detailed parametric studies have been carried out including all the major lengths, widths, feed lines, and positions of rectangular strips to achieve higher gain of the proposed design.

3.2. Current Distribution and Impedance Matching Analysis. Figure 6 shows the current distribution on the antenna at $2.4 \mathrm{GHz}$ and $3.4 \mathrm{GHz}$ to get a better insight of the antenna design which depicts that the current varies along the antenna $x$-axis dimension with minimum current at the ends due to the reduced "end effect." As a matter of fact antenna radiates energy because of radiation resistance. Loss resistance of the antenna is small compared to radiation resistance that is usually considered negligible in measurements. Input pulse and corresponding electric field intensity are calculated by the following expression:

$$
\mathrm{FF}=\frac{\max }{\tau}\left\{\frac{\int S_{T}(t) S_{R}(t-\tau) d t}{\sqrt{S_{T}^{2}(t) d t} \sqrt{S_{R}^{2}(t) d t}}\right\},
$$

where " $S_{T}$ " is the input signal and " $S_{R}$ " is the received signal in the antenna far-field. Using Ansoft's HFSS, fullwave time domain results are studied. Maximum current at top strip is obtained on both frequencies which have 90-degree phase shift that justifies the inductance of top cladding strip. The rounded corner concept serves well as it reflected more and more energy to the metal strips at resonant bands. Nevertheless, consistent large current density is concentrated on top strip for both frequency bands as common characteristics.

Figure 7 show the real and imaginary components of the input impedance of final two designs. Rounded corners model is tightly aligned to $50 \Omega$ line in real part and has less tolerance in case of imaginary part. Overall better impedance matching is achieved by rounded corners design for both first and second resonance bands.

3.3. Results and Parametric Study. Figure 8 shows the simulated and measured results of reflection coefficients $S_{11}[\mathrm{~dB}]$ versus frequency of the final proposed CPW antenna. It is shown that the antenna covers two ultrawide bands which include $1.1 \mathrm{GHz}-2.7 \mathrm{GHz}$ and $3.15-3.65 \mathrm{GHz}$, thus covering 2.4 GHz Bluetooth/Wi-Fi band (IEEE 802.11, 2.4-2.48 GHz) and most of the bands of $3 \mathrm{G}, 4 \mathrm{G}$ such as IEEE 802.15.4 (2.5-2.69 GHz, 3.4-3.69 GHz), WiMAX (IEEE 802.16), ZigBee (IEEE 802.15.4), DCS (1800), PCS (1900 MHz), Extended IMT $(2100 \mathrm{MHz})$, and LTE $(1700,1900 \mathrm{MHz})$, and a future expected $5 \mathrm{G}$ band, that is, $3.4-3.6 \mathrm{GHz}$. There is generally a good agreement between simulated and measured results where differences between simulated and measured results can be attributed to factors such as small antenna size, SMA connector quality, soldering effect, and uncertainties in substrate dielectric constant. Major rectangular/circular slot size and lengths/widths of both top and bottom strips are optimized during designing process. The effects of variations in the width of bottom strip on the reflection coefficient $S_{11}$ are plotted in Figure 9. It is experienced that the first resonance frequency increases with the decrease in the width of bottom strip and has negligible effect on second band, while variation of top strip controls the $3.4 \mathrm{GHz}$ resonance frequency (second resonance band) that makes it simple and easy to reconfigure design for other adjacent frequencies if needed. The gains of the antennas with and without rounded edges/circular slot in $\mathrm{dB}$ versus frequency are shown in Figure 10. Comparing Antenna 3 and Antenna 4, the value of peak gain is subsequently improved from $6.2 \mathrm{~dB}$ to $8.9 \mathrm{~dB}$. This shows that the gain is reasonably increased when the bottom strip edges are rounded and circular slot are overlapped on some of the corners of the upper strip which depicts the variation in gain between $6.2 \mathrm{~dB}$ and $8.9 \mathrm{~dB}$ in the range of interest. 


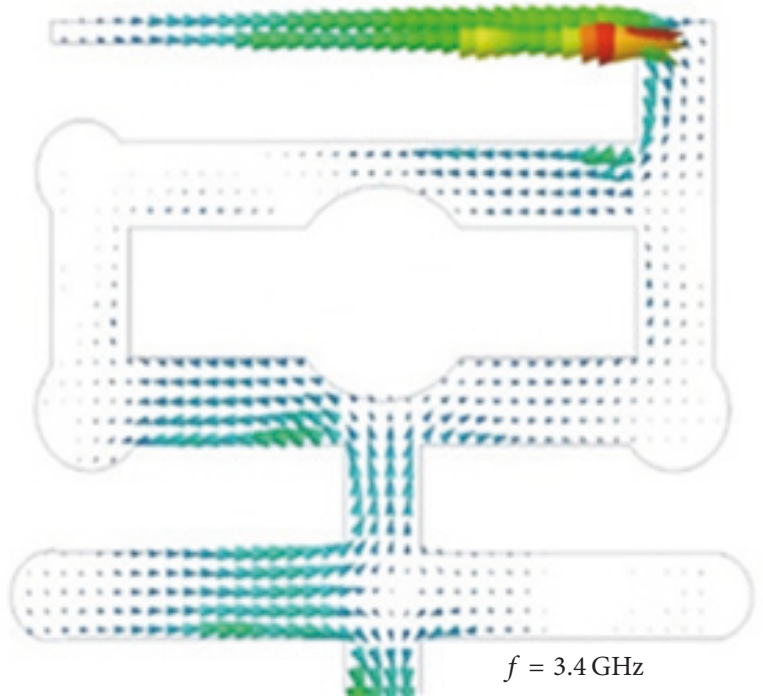

(a)

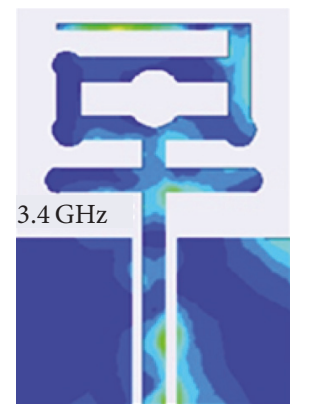

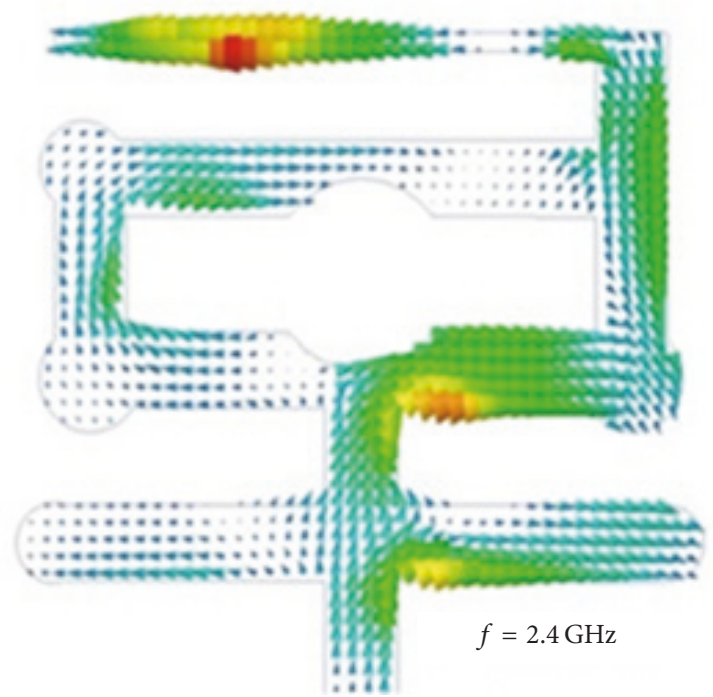

(b)

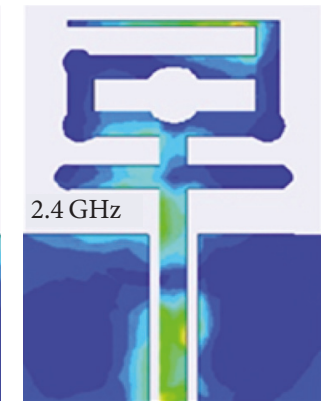

Jsurf (A_per_m)

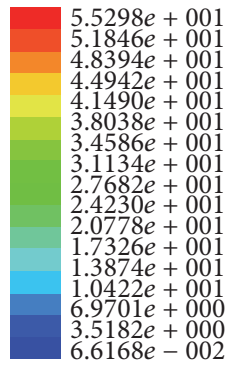

(c)

FIGURE 6: Current distribution on the proposed antenna: (a) vector current distribution at $3.4 \mathrm{GHz}$, (b) Vector current distribution at $2.4 \mathrm{GHz}$, and (c) Current densities at $2.4 \mathrm{GHz}$ and $3.4 \mathrm{GHz}$.

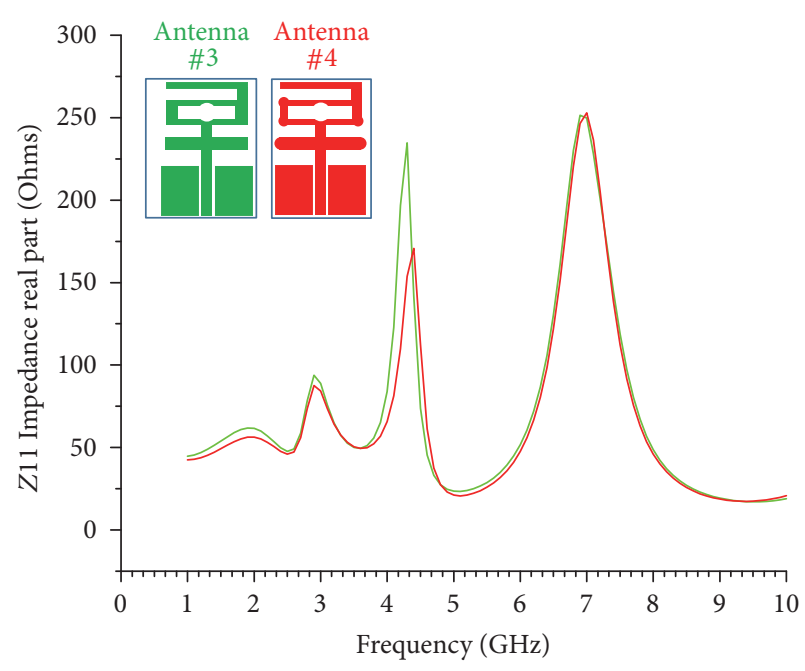

- Antenna 3

— Antenna 4

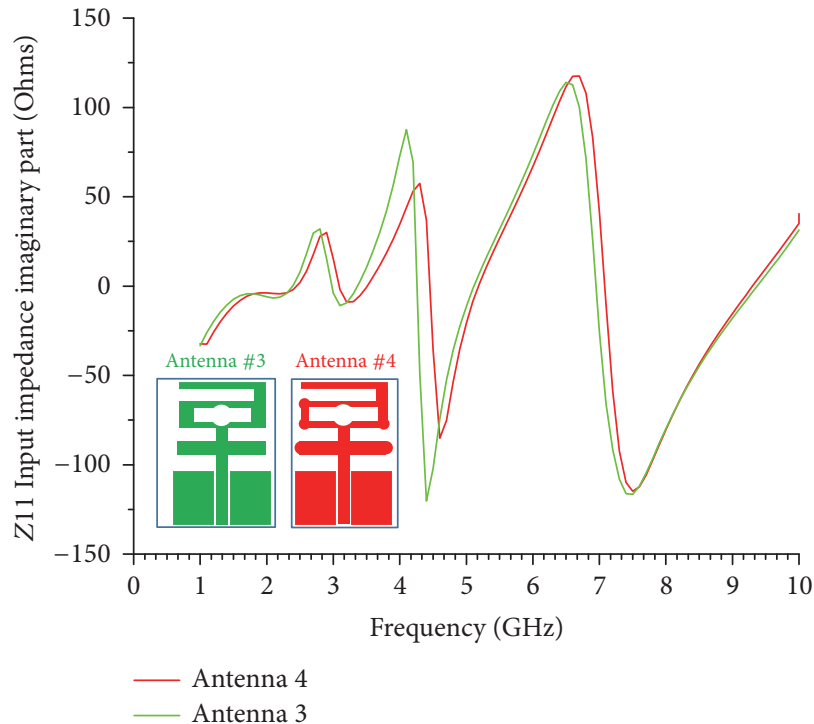

(b)

FIGURE 7: Input impedance of the final two designs: (a) real part (b) imaginary part. 


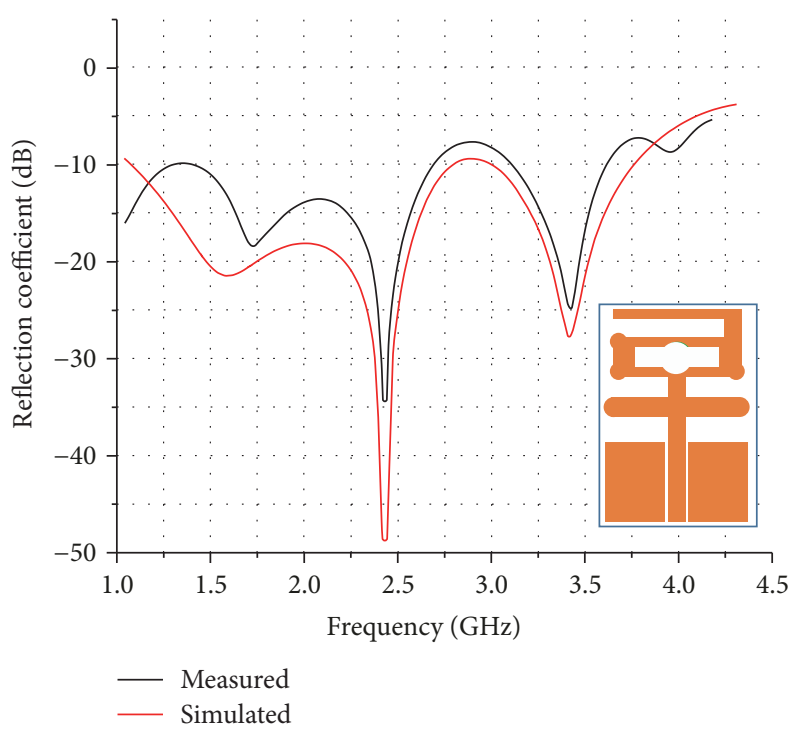

FIGURE 8: The simulated and measured refection coefficients $S_{11}[\mathrm{~dB}]$ versus frequency $[\mathrm{GHz}]$ of the proposed antenna.

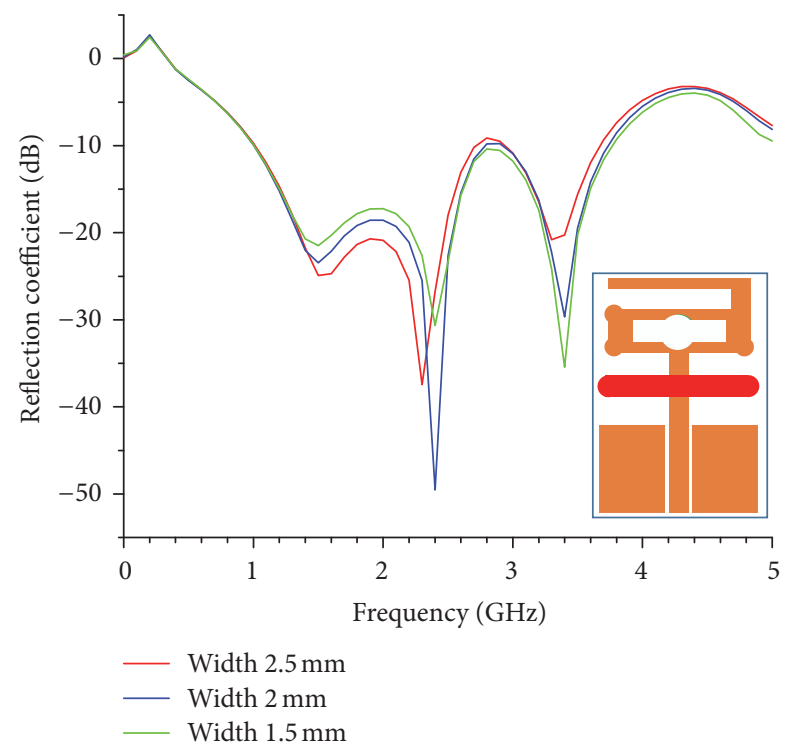

FIGURE 9: Reflection coefficient $S_{11}$ in $[\mathrm{dB}]$ versus frequency in $\mathrm{GHz}$ for variations in the width of the lower strip.

The radiation patterns of this dual-band antenna at first and second resonance bands are illustrated in Figure 11 for both $E$ - and $H$-planes. High order modes are responsible to generate distribution effect at higher frequencies. It is clearly evident from the $2 \mathrm{D}$ patterns that the antenna performs as a directional radiator at $E$-plane and quite close to bidirectional in $H$-plane. These characteristics make this novel design a strong candidate and effectively suitable for profound Internet of Things (IoT) applications.

\section{Conclusion}

In this article, a novel rectangular shape CPW antenna with overlapped circular slots and rounded edges is proposed

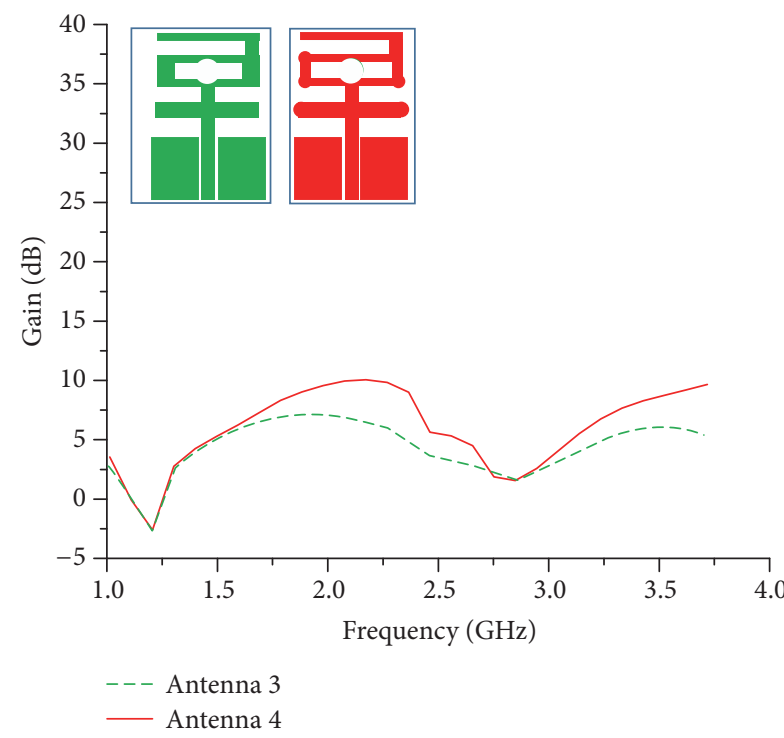

FigURE 10: The gains of the antennas with and without the rounded edges/circular slot in $\mathrm{dB}$ versus frequency in $\mathrm{GHz}$.

and implemented. Top strip and bottom strips effectively control $2.4 \mathrm{GHz}$ and $3.4 \mathrm{GHz}$ resonance bands. Rounded corners technique is used to attain ultrawide bandwidth of $1.1 \mathrm{GHz}-2.71 \mathrm{GHz}$ at first resonance band and $3.15-3.65 \mathrm{GHz}$ for second resonance band and to improve antenna gain. Each of these bands can be individually tuned through variation of top and bottom strip dimensions. The proposed antenna shows directional radiation pattern, good return loss, and better gain with acceptable radiation efficiency. The proposed design is very small in size $\left(875 \mathrm{~mm}^{2}\right)$ which makes it a suitable contender for different portable and handheld IoT applications. 

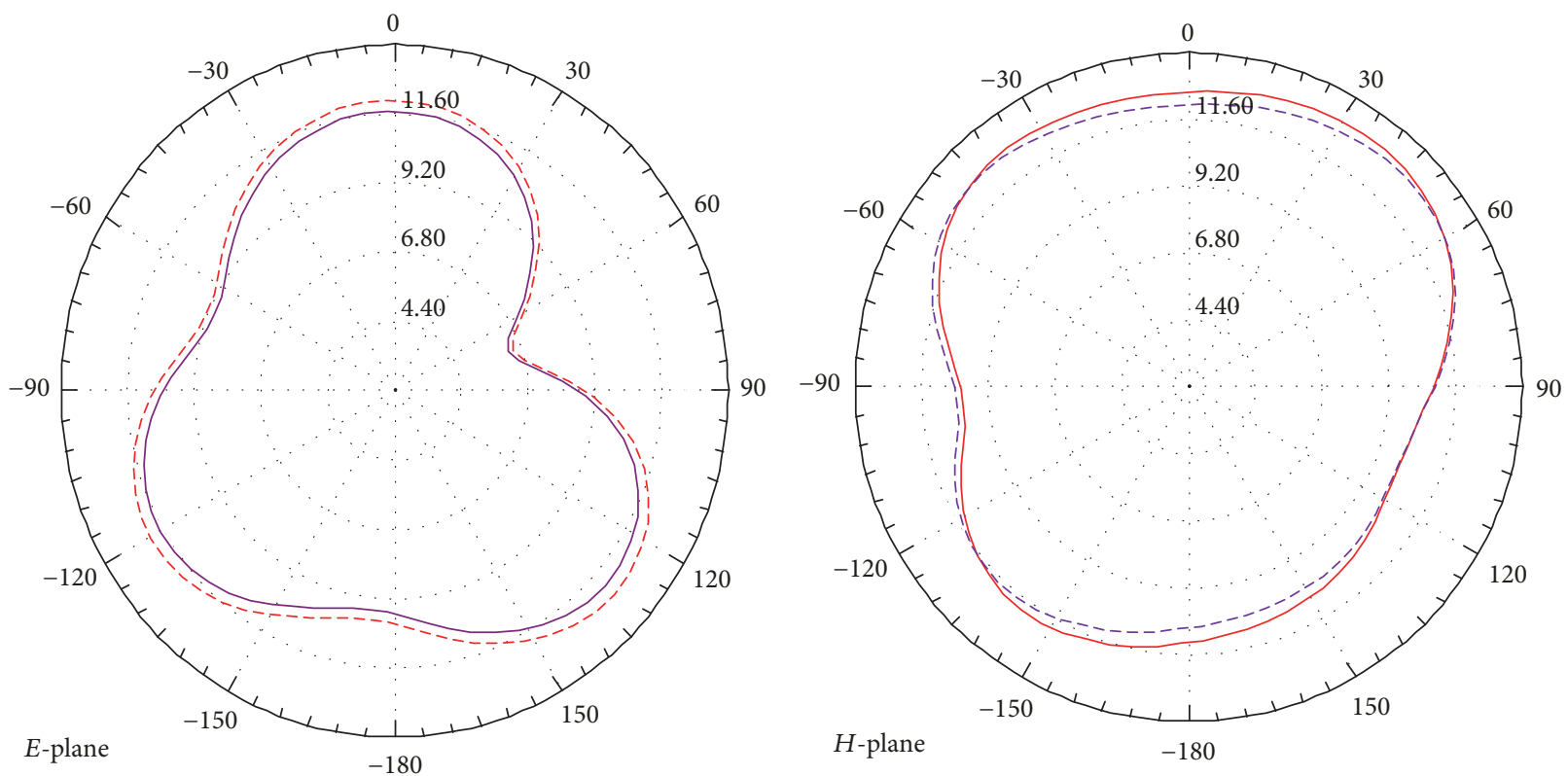

- - Simulated

- Measured

(a)

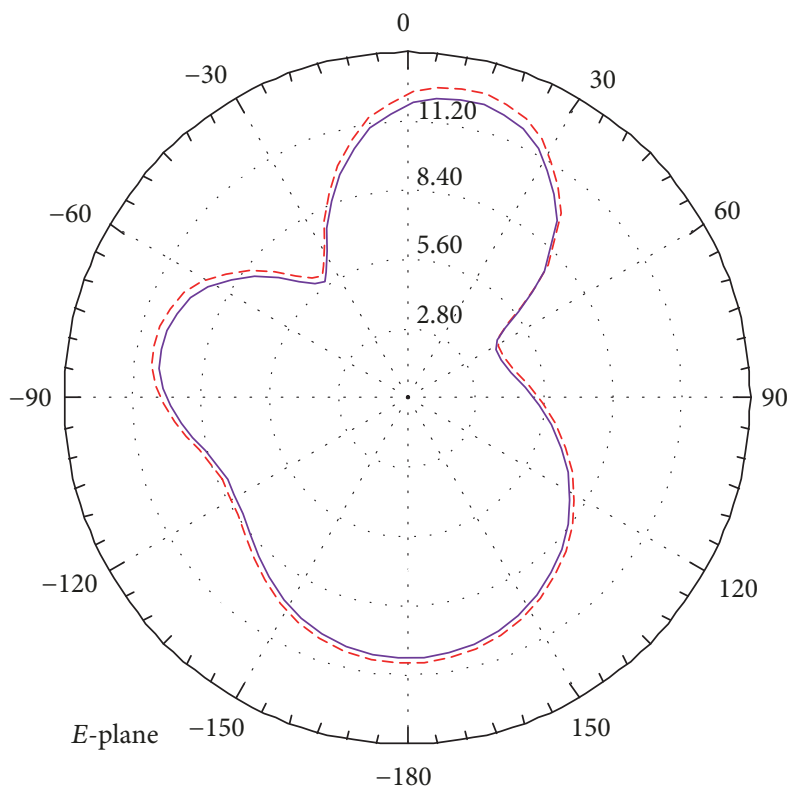

(c)

(b)

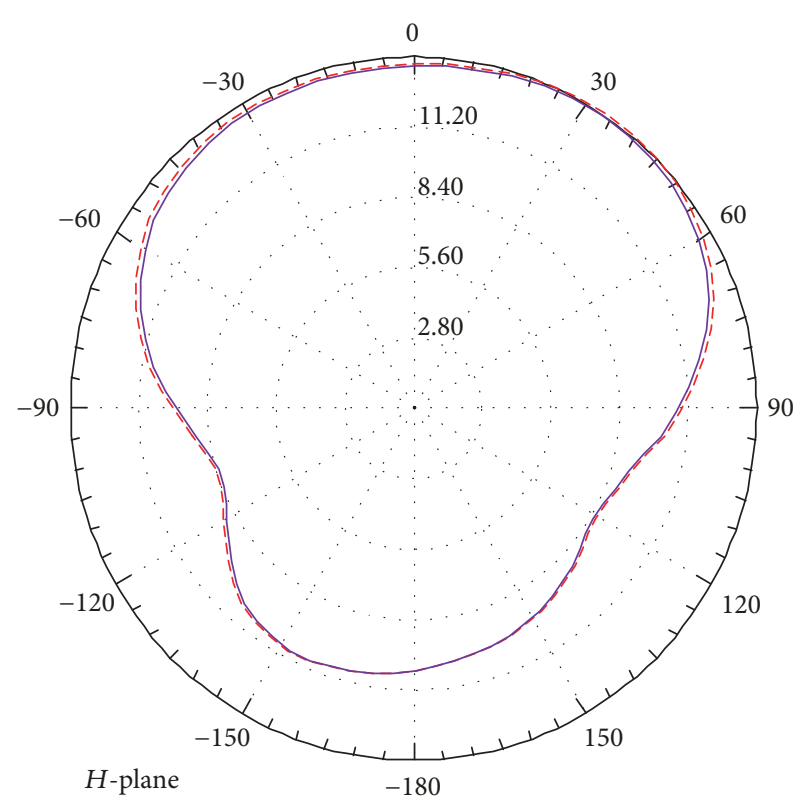

(d)

FIGURE 11: 2D radiation patterns of the proposed antenna: (a) E-plane at $2.4 \mathrm{GHz}$, (b) $H$-plane at $2.4 \mathrm{GHz}$, (c) E-plane at $3.4 \mathrm{GHz}$, and (d) $H$-plane at $3.4 \mathrm{GHz}$.

\section{Conflicts of Interest}

The authors declare that there are no conflicts of interest regarding the publication of this paper.

\section{References}

[1] D. Acharjya and M. K. Geetha, "Internet of Things: Novel Advances and Envisioned Applications," in Internet of Things: Novel Advances and Envisioned Applications, Springer, 2017.
[2] S. C. Mukhopadhyay and N. K. Suryadevara, "Internet of things: Challenges and opportunities," Smart Sensors, Measurement and Instrumentation, vol. 9, pp. 1-17, 2014.

[3] G. J. Jo, S. M. Mun, D. S. Im, G. R. Kim, Y. G. Choi, and J. H. Yoon, "Novel design of a CPW-FED monopole antenna with three arc-shaped strips for WLAN/WiMAX operations," Microwave and Optical Technology Letters, vol. 57, no. 2, pp. 268273, 2015.

[4] A. Z. Manouare, S. Ibnyaich, A. El Idrissi, and A. Ghammaz, "Miniaturized triple wideband CPW-fed patch antenna with a 
defected ground structure for WLAN/WiMAX applications," Journal of Microwaves, Optoelectronics and Electromagnetic Applications, vol. 15, no. 3, pp. 157-169, 2016.

[5] T. Naeem, F. A. Tahir, and A. I. Najam, "UWB antenna with notches at WLAN bands," in Proceedings of the 11th International Conference on Frontiers of Information Technology, FIT 2013, pp. 172-176, Pakistan, December 2013.

[6] S. Ahmed, F. A. Tahir, A. Shamim, and H. M. Cheema, "A compact kapton-based inkjet-printed multiband antenna for flexible wireless devices," IEEE Antennas and Wireless Propagation Letters, vol. 14, pp. 1802-1805, 2015.

[7] A. Moradhesari, M. Naser-Moghadasi, and F. G. Gharakhili, "Design of compact CPW-FED monopole antenna for WLAN/WiMAX applications using a pair of F-shaped slits on the patch," Microwave and Optical Technology Letters, vol. 55, no. 10, pp. 2337-2340, 2013.

[8] V. A. Shameena, S. Mridula, A. Pradeep, S. Jacob, A. O. Lindo, and P. Mohanan, "A compact CPW fed slot antenna for ultra wide band applications," AEU - International Journal of Electronics and Communications, vol. 66, no. 3, pp. 189-194, 2012.

[9] T. H. Kim and D. C. Park, "CPW-fed compact monopole antenna for dual-band WLAN applications," IEEE Electronics Letters, vol. 41, no. 6, pp. 291-293, 2005.

[10] J. H. Yoon, "Fabrication and measurement of rectangular ring with open-ended CPW-fed monopole antenna for $2.4 / 5.2-\mathrm{GHz}$ WLAN operation," Microwave and Optical Technology Letters, vol. 48, no. 8, pp. 1480-1483, 2006.

[11] L. Chen, Y.-F. Liu, and X.-L. Ma, "Compact ACS-Fed circular-ARC-shaped stepped monopole antenna for tri-band WLAN/WiMAX applications," Progress in Electromagnetics Research C, vol. 51, pp. 131-137, 2014.

[12] L. Chen, Y.-L. Luo, and Y. Zhang, "Compact tri-band planar monopole antenna with ACS-fed structure," Progress in Electromagnetics Research Letters, vol. 49, pp. 45-51, 2014.

[13] V. Deepu, R. Sujith, S. Mridula, C. K. Aanandan, K. Vasudevan, and P. Mohanan, "ACS FED printed F-shaped uniplanar antenna for dual band WLAN applications," Microwave and Optical Technology Letters, vol. 51, no. 8, pp. 1852-1856, 2009.

[14] B. Li, Z. Yan, and T. Zhang, "Triple-band slot antenna with U-shaped open stub fed by asymmetric coplanar strip for WLAN/WiMAX applications," Progress in Electromagnetics Research Letters, vol. 37, pp. 123-131, 2013.

[15] X. Li, X.-W. Shi, W. Hu, P. Fei, and J.-F. Yu, "Compact triband ACS-Fed monopole antenna employing open-ended slots for wireless communication," IEEE Antennas and Wireless Propagation Letters, vol. 12, pp. 388-391, 2013.

[16] Y. Li, W. Li, and R. Mittra, "A compact ACS-FED dualband meandered monopole antenna for WLAN and WiMAX applications," Microwave and Optical Technology Letters, vol. 55, no. 10, pp. 2370-2373, 2013.

[17] Y.-F. Liu, P. Wang, and H. Qin, "A compact triband ACSfed monopole antenna employing inverted-L branches for WLAN/WiMAX applications," Progress in Electromagnetics Research C, vol. 47, pp. 131-138, 2014.

[18] P. V. Naidu and R. Kumar, "Design of a compact ACS-Fed dual band antenna for bluetooth/WLAN and WiMAX applications," Progress in Electromagnetics Research C, vol. 55, pp. 63-72, 2014.

[19] Y. Song, Y. C. Jiao, X. M. Wang, Z. B. Weng, and F. S. Zhang, "Compact coplanar slot antenna fed by asymmetric coplanar strip for 2.4/5 GHz WLAN operations," Microwave and Optical Technology Letters, vol. 50, no. 12, pp. 3080-3083, 2008.

[20] X. L. Sun, S. W. Cheung, and T. I. Yuk, "A compact monopole antenna for WLAN applications," Microwave and Optical Technology Letters, vol. 56, no. 2, pp. 469-475, 2014.

[21] C.-K. Ham, J.-W. Baik, and Y.-S. Kim, "CPW-FED compact meander and L-shape monopole antenna for dual-band WLAN applications," Microwave and Optical Technology Letters, vol. 50, no. 12, pp. 3147-3149, 2008.

[22] I. Zahraoui, J. Zbitou, A. Errkik et al., "A novel design of a low cost CPW fed multiband printed antenna," Lecture Notes in Electrical Engineering, vol. 380, pp. 3-8, 2016.

[23] S. Ashok Kumar, T. Shanmuganantham, and D. Dileepan, "Design and development of CPW fed monopole antenna at $2.45 \mathrm{GHz}$ and $5.5 \mathrm{GHz}$ for wireless applications," Alexandria Engineering Journal, vol. 56, no. 2, pp. 231-234, 2017.

[24] Y. M. Madany and H. Elkamchouchi, "Analysis of high gain multiband rounded corners dashed rectangular spiral microstrip patch antenna," in Proceedings of the 2005 IEEE Antennas and Propagation Society International Symposium and USNC/URSI Meeting, pp. 313-316, USA, July 2005.

[25] P. V. Naidu and R. Kumar, "A very small asymmetric coplanar strip fed multi-band antenna for wireless communication applications," Microsystem Technologies, vol. 22, no. 9, pp. 2193-2200, 2016.

[26] S. W. Qu and C. L. Ruan, "Effect of round corners on bowtie antennas," Progress in Electromagnetics Research, vol. 57, pp. 179195, 2006.

[27] J. J. Tiang, M. T. Islam, N. Misran, and J. S. Mandeep, "A rounded corner triangular patch antenna for dual-frequency application," Microwave and Optical Technology Letters, vol. 56, no. 1, pp. 69-72, 2014.

[28] K. Van Caekenberghe, N. Behdad, K. M. Brakora, and K. Sarabandi, "A 2.45-GHz electrically small slot antenna," IEEE Antennas and Wireless Propagation Letters, vol. 7, pp. 346-348, 2008.

[29] P. K. Bharti, H. Singh, G. Pandey, and M. Meshram, "Slot loaded microstrip antenna for GPS, Wi-Fi, and WiMAX applications survey," International Journal of Microwaves Applications, vol. 2, 2013.

[30] K. Vyas, G. Sanyal, A. K. Sharma, and P. K. Singhal, "Gain enhancement over a wideband in CPW-fed compact circular patch antenna," International Journal of Microwave and Wireless Technologies, vol. 6, no. 5, pp. 497-503, 2014.

[31] S. I. Latif, L. Shafai, and S. K. Sharma, "Bandwidth enhancement and size reduction of microstrip slot antennas," IEEE Transactions on Antennas and Propagation, vol. 53, no. 3, pp. 994-1003, 2005.

[32] P. V. Naidu, "Design, Simulation of a Compact Triangular Shaped Dual-Band Microstrip Antenna for $2.4 \mathrm{GHz}$ Bluetooth/WLAN and UWB Applications," Wireless Personal Communications, vol. 95, no. 2, pp. 783-794, 2017.

[33] M. M. M. Rahman, Design and performance analysis of $u$-slot, $y$ slot and uy slot microstrip patch antenna for wireless applications, Daffodil International University, 2016.

[34] M. Kumar and K. Ray, "Design and Performance of a compact broadband circularly polarized rectangular ring antenna," International Journal of Electromagnetics and Applications, vol. 4, pp. 49-55. 


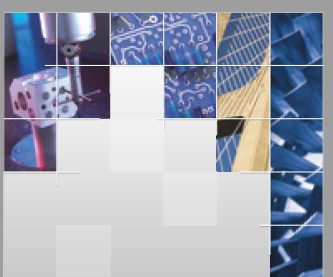

\section{Enfincering}
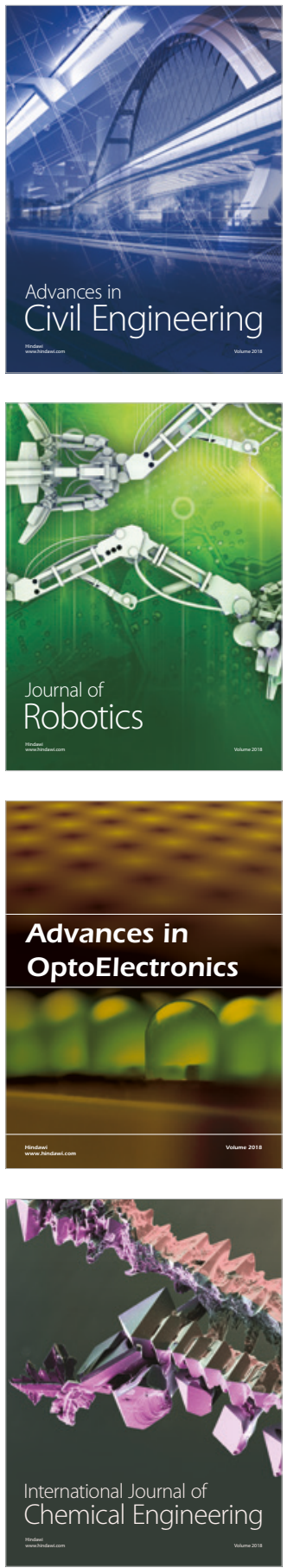

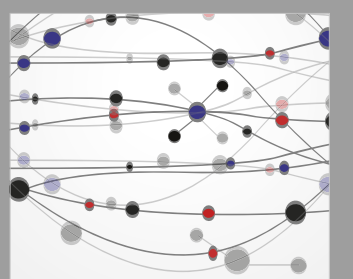

\section{Rotating \\ Machinery}

The Scientific World Journal

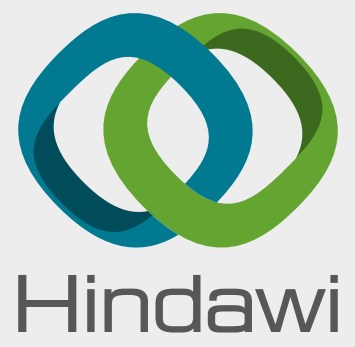

Submit your manuscripts at

www.hindawi.com
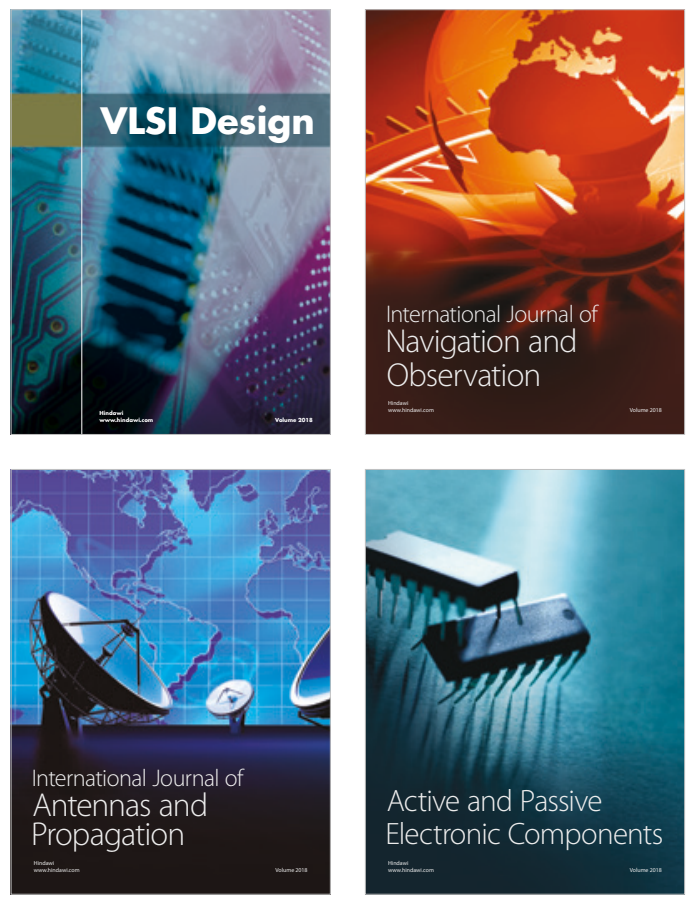
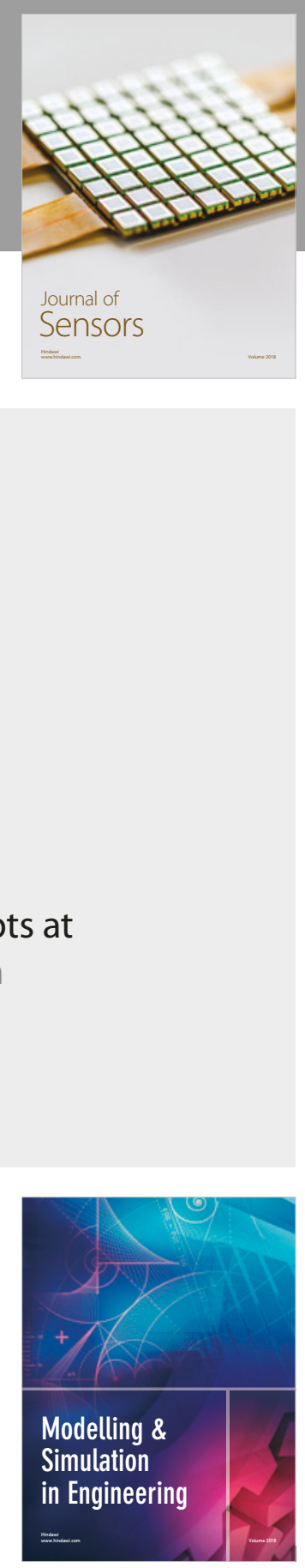

\section{Advances \\ Multimedia}
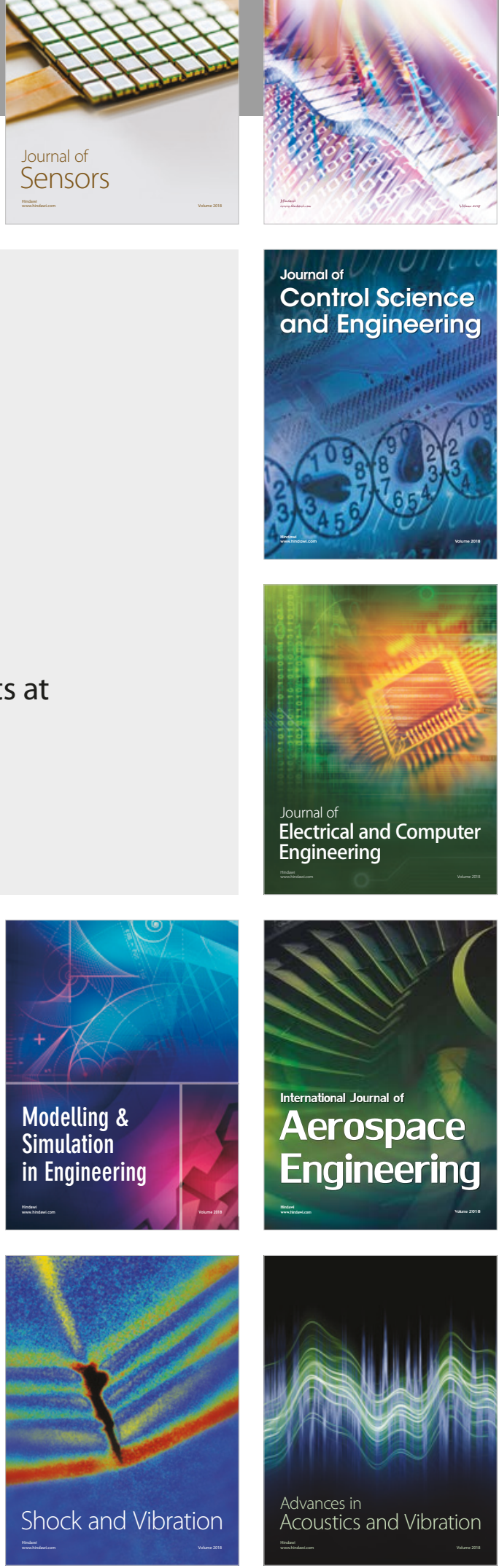